\title{
Evaluation of reproductive health program during disaster in West Sumatra Province
}

\author{
Azrimaidaliza $^{1 *}$ Qori Andayani Putri ${ }^{2}$, and Yessy Markolinda ${ }^{2}$ \\ ${ }^{1}$ Departement of Nutrition, Faculty of Public Health, Andalas University, West Sumatra, Indonesia \\ ${ }^{2}$ Departement of Public Health Science, Faculty of Public Health, Andalas University, West Sumatra, Indonesia
}

\begin{abstract}
Indonesia is one of the countries with the highest disaster risk. Disaster could affect all aspects of human life including reproductive health. The study aims to evaluate reproductive health programs during disasters. The study was conducted with a qualitative study regarding the system approach. There were 19 informants from health centers, disaster management agencies, and social institutions in the South of West Sumatra Province. Data was collected through in-depth interviews, focus group discussions, and document reviews. Data analysis used content analysis. In the input component, there has been no policy for reproductive health, double responsibility on human resources, and the budget from disaster management for existing facilities. In the process component, a plan for the reproductive health programs does not exist yet and no specific team of health reproductive. The implementation of reproductive health services was data collection, assessment of needs, reproductive health care, and monitoring will be done after a disaster. In the output component, the coverage of indicators for women of childbearing age has been well-served, but not for young women. Management of reproductive health programs is not optimal yet. It is recommended to improve the management of reproductive health programs before, during, and after disasters.
\end{abstract}

\section{Introduction}

A disaster is an event or series of events that can threaten and disrupt people's lives caused by natural and nonnatural factors. Disasters can result in human casualties, natural damage, property losses, and also psychological impacts [1]. Data from 128 developing countries in the world found that the average number of deaths from natural disasters and armed conflict in East Asia and the Pacific region was not significantly different from the rest of the developing world [2].

Indonesia is amongst the countries with the highest disaster risk in the world [3]. Demographic, geological, and geographical of Indonesian situation are the factors that contribute to the risk of disaster happened. Based on the Indonesian Disaster Information Data (DIBI), the number of disaster events that occurred in Indonesia has increased over the last three years, namely, there were 1,694 disasters in 2016, 2,306 disasters in 2017, and 2,397 disasters in 2018 throughout Indonesia [4].

According to the Regional Disaster Management Authority report, West Sumatra Province has four main potential disasters, namely the potential for landslides, floods, earthquakes, and tsunamis [5]. Several areas in West Sumatra Province are areas prone to natural disasters, especially flash floods, and have a high impact on disaster events [5].
Disaster cases that occur will cause health crises, including paralysis of health services, fatalities, injured victims, refugees, nutritional problems, problems with the availability of clean water, environmental sanitation problems, infectious diseases, and psychiatric disorders, and disruption of reproductive health services, especially on women's groups [6,7]. Fact, reproductive health services during disasters are often not available because they are not considered a priority, even though there are always pregnant women, mothers in labor, and newborns who need help. Reproductive health services that are not available during disasters such as Antenatal Care (ANC) services and services for adolescent girls [8].

Reproductive health services in overcoming the health crisis are implemented through the Minimum Initial Service Package (MISP) for reproductive health. The MISP will be able to prevent reproductive health problems that will arise, such as preventing and dealing with sexual violence, reducing HIV transmission, preventing increased maternal and neonatal morbidity and mortality [9].

Based on the research of Siti Nuruniyah (2014), it is found that there were 3 cases of sexual harassment in the refugee camps resulting from reproductive health services during the disaster that was not optimal in terms of input. It might have happened because there were no operational policies and organizational structures and infrastructure

\footnotetext{
*Corresponding Author: azrimaidaliza@ph.unand.ac.id
} 
facilities were not widely available such as intimate booths, tools, and equipment. Besides that there was no contraception and bathrooms were not separated between men and women. The study has also identified that process of monitoring and evaluation has not been carried out in a structured manner. Meanwhile, in terms of output, the responsible team has not yet been formed and not all officers and the community can use the existing inputs [10].

In February 2018, there was a flash flood that hit one area in the south of West Sumatra Province. The disaster caused one of the villages to feel the impact. The disaster resulted in the death of one person, 3 units of heavy houses, and 4,000 housing units submerged by floods, and as many as 781 families were affected and evacuated. Then there was one area that was worst hit by the flash flood disaster and the people were evacuated to the evacuation post. Based on the results of an interview with the head of the area, it was stated that the community affected by the disaster had received general health services such as health checks and additional food for babies from the health center. As for the provision of assistance, It was conducted by a local disaster management agency and social service $[11,12]$.

According to the data and the previous studies, the study aimed to describe and evaluate reproductive health programs during a disaster in one of the areas in the South of West Sumatra Province which had experienced a disaster. The research used a systems approach consisting of input, process, and output.

\section{Methodology}

This type of research is a qualitative study using a systems approach to know in detail about health reproductive programs consisting of input, process, and output components.

\begin{tabular}{|c|c|c|}
\hline$\stackrel{\text { Input }}{\text { Components }}$ & $\stackrel{\text { Process }}{\text { Components }}$ & 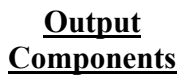 \\
\hline $\begin{array}{l}\text { Policy } \\
\text { Human } \\
\text { Resources } \\
\text { Budget } \\
\text { Facilities }\end{array}$ & $\begin{array}{l}\text { Planning } \\
\text { Organizing } \\
\text { Implementation } \\
\text { Monitoring }\end{array}$ & $\begin{array}{l}\text { Program } \\
\text { coverage }\end{array}$ \\
\hline
\end{tabular}

Fig. 1. System Approach in Research of Reproductive Health Program Evaluation

The research was held in one region in the South of West Sumatra Province, specifically in health institutions, local disaster management agencies, and Social Institutions. 19 informants were carried out by purposive sampling and agreed to participate in the study.

Data was collected through in-depth interviews with the standard of interview guidelines, Focus Group Discussion or FGD, and document review. The input data component consisted of policy, human resources, budget, and facilities. Process component consisted of planning, organizing, implementation, and monitoring. Then, the output component was coverage of the reproductive health program. After that, data were analyzed by the content analysis method.

\section{Analysis and Discussion}

We evaluated the input components which consisted of policies, Human Resources (HR), funds, and infrastructures or facilities. Based on interviews and document review, there was no policy regarding special programs for reproductive health during disasters. But the reference was based on disaster guidelines, namely Law Number 24 of 2007 concerning disaster management and guidelines for the MISP. Human resources for reproductive health at the time of a disaster at the Health Office did not yet exist, but when a disaster occurred related to reproductive health, it was assigned to village midwives who were assisted by nurses. There is no special budget for reproductive health during the disaster, but it is combined with the budget for disaster management sourced from the budget income expenditure. Availability of facilities or infrastructure for reproductive health during a disaster, namely utilizing existing facilities and infrastructure.

The process component consists of planning, organizing, implementing, and monitoring. Based on the results of the in-depth interview, FGD, and document review that there was no specific reproductive health program planning during the disaster. The activities were included with all disaster-related programs and coordinated with the cross-sector of disaster. Those involved in the management of reproductive health programs were in the field of public health, especially the section on family health and nutrition. Meanwhile, at the health center, it is conducted by the worker of the maternal-child health program. Reproductive health services provided during a disaster are the provision of blood-added tablets and general health checks. The community received assistance in the form of food, clothing, blankets, kitchen utensils, towels, and toiletries, but disaster victims, especially women of childbearing age and teenagers, did not receive assistance in the form of menstrual pas. Supervision of reproductive health programs during a disaster is carried out directly by visiting the refugee camps for disaster victims and those who carry out supervision can be the head of the health center and the health office.

The output component is based on the results of indepth interviews, FGD, and document review that the Health Service, Health Center, local disaster management agency, and social service do not yet have specific indicators for reproductive health but for disaster indicators in general they have been implemented well. Reproductive health services and needs for reproductive women and young women were still not fulfilled.

\subsection{Input Component}

\subsubsection{Policy}

Based on the results of the research that policies for reproductive health during disasters in the Regency had 
not yet been written because policies regarding disasters were still the responsibility of the Provincial Health Office. The guidelines that have been used as a reference during disasters so far are general disaster guidelines, namely Law Number 24 of 2007 concerning disaster management and guidelines for the MISP of reproductive health in health crises.

The finding was also in line with the research of Siti Nuruniyah (2014) in her research on reproductive health services for refugees stating that the policy basis used is based on Law Number 24 of 2007 concerning disaster management and local regulation number 31 of 2010 concerning the state of emergency response, but policies in the form of decrees and standard operating procedures were not yet existed [13].

\subsubsection{Human Resources}

The results showed that there were no specific health workers which were involved in reproductive health programs during the disaster. The performance of the health workers was under the competence and educational background. Only a few health workers received special training for reproductive health during the disaster, namely only 1 worker who had received training twice. The staff also knew the MISP guidelines and the reproductive health kit during the training. In this health center, there had not been a special team for reproductive health during the disaster.

This result was consistent with research by Siti Nuruniyah (2014). The current research stated that human resources were not yet available specifically for reproductive health services for refugees. Health human resources took care of all health problems as a whole in the refugee camps [13]. Based on the MISP manual, a coordinator for reproductive health services in emergency response situations must be appointed to coordinate across programs, across sectors, local and international institutions [14].

\subsubsection{Budget}

The results of the study showed that there was no special budget for reproductive health during the disaster, but it was combined with the budget for disaster management sourced from state revenue funding or APBN and regional expenditure budget or APBD. The overall availability of budget during the disaster at the Health Service, Social Service, and Regional Disaster Management Agency was not sufficient, but the health center was sufficient.

Based on the results of Sandra Krause's (2013) research on reproductive health services for refugees in Jordan, it was stated that there was a gap in funding and equipment as an obstacle in implementing the MISP in Jordan [15]. According to Decree of the Minister of Health of the Republic of Indonesia No. 145 of 2007 concerned to guidelines for disaster management in the health sector that the budget for disaster management use disaster budgets allocated by each Regency, City, or Province. If there are deficiencies, they can propose in stages from the Regency, City, Provincial, and Central levels.

Determining how much financial loss results from a natural disaster is not an easy task and budgeting in advance for a disaster could be far more complicated. The need for a budget according to disaster depends on expenditure for pre-disaster, emergency response, and post-disaster. Heru Fahlevi's study (2019) found that the total budget of the local governments has a significant positive correlation with the disaster budget in Aceh Province, Northern Indonesia. The surveys also identify the correlation between the total budget of the local government and disasters as the same budgeting procedure is applied [16].

\subsubsection{Facilities}

The results showed that the availability of logistics for reproductive health during a disaster was partially available. Meanwhile, at Regional Disaster Management Authority and the Social Service, there were also infrastructure facilities such as logistics warehouses, evacuation equipment, and equipment needed during disaster management. The existing infrastructure when a disaster occurs was 1 unit of an ambulance and a special tent for health checks for victims.

Based on the results of the study that the lack of facilities and infrastructure were operational vehicles that only had 1 unit of an ambulance for patient referrals during a disaster. The situation was made it difficult for health officers in the health center to go back and forth to refer patients from the disaster scene to the health center.

The results of research from Siti Nuruniyah (2014) stated that reproductive health infrastructure such as sterile delivery kits for maternal and neonatal emergency medicines was not yet available in evacuation centers and referral cars to limited health care facilities [13].

\subsection{Process Component}

\subsubsection{Planning}

Based on the results of the study, it was shown that there was no specific planning for reproductive health programs during the disaster, but the plan is still joined with all programs and coordinated with cross-sectors related to disasters.

The result of the study was in line with research conducted by Sanaz Sohrabizadeh (2018) that there was no pre-disaster planning for reproductive health services during a disaster. This can be seen from the lack of coordination between local, regional, and national health systems. Another consequence of the lack of planning is the lack of equipment and limited human resources faced by health centers in providing reproductive health services in the post-disaster period [17].

\subsubsection{Organizing}

The results showed that there was no specific organizational structure for reproductive health during the 
disaster, but the overall structure was used. Those involved in the management of reproductive health programs are in the field of public health, especially the section on family health and nutrition. While at the health center is done of the Maternal and Child Health program.

According to the MISP Guidelines for dealing with reproductive health during a disaster, an organization consisting of a reproductive health coordinator as the Chairperson and team members who are responsible for the components of gender-based violence, prevention of HIV transmission, maternal and neonatal health, and logistics is formed [9].

The study was in line with current the study in East Lombok. the management of reproductive health postearthquake was not well organized. The study also identified that the organizational structure for managing the district-level health care program, both during the emergency response and rehabilitation phase, has not yet been formed [18].

\subsubsection{Implementation}

The program of reproductive health was for during disaster, and there is no program of reproductive health before and after the disaster. Reproductive health services during the disaster were provided by giving tablets from the health center to add blood and general health checks. During a disaster emergency response situation, the Health Service had also coordinated with a local disaster management agency, social service, armed forces, and police to evacuate disaster victims and provide first aid for victims' needs. When the situation stabilized, the victim was given food and clothing assistance, but the victim did not receive assistance related to reproductive health such as menstrual pads, and was also not given food assistance for mothers who have children under five.

The result of the study is consistent with the research conducted by Suryati (2013), The study found that the needs of young women during menstruation in disaster emergencies, $95.10 \%$ need a menstrual pad, $55.24 \%$ need underwear, and $19 \%$ need medicine, but during a disaster, these needs have not been met [8]. Disasters have a significant impact on the reproductive health conditions of the affected residents, especially women of childbearing age, children, and young women, these impacts include increased maternal and neonatal deaths, increased risk of cases of sexual violence and further complications, increased transmission of Sexually Transmitted Infections (STIs), the occurrence of unwanted pregnancies and unsafe abortions, as well as the increasing spread of HIV [8].

A study by Nurhidayati in 2020 found that health workers' types of service activities after the earthquake are midwives, nurses, and doctors from the unaffected health center. The activities routinely include antenatal care, delivery assistance, high-risk detection, and case referral. Some services were not provided, namely family planning services and contraceptives. The study also found that there was an increase in mothers' and neonates' high-risk cases and an increase in pregnant women in the first trimester during the rehabilitation period. Provision of reproductive health tent for delivery services, pregnant women, and maternity services is available in collaboration with overseas organizations, but there is only one for the entire district in East Lombok. Limited facilities, logistics, sanitation, and health workers are also less sensitive to other basic needs [18].

Reproductive health program for women is not only conducted during the disaster but also after the disaster. The program which provides for the identified sexual and reproductive health needs is conducted in terms to follow the guidance of the Minimum Initial Service Package by the global Inter-Agency Working Group. Reproductive health services are included the distribution of medical camp kits, the deployment of nurses with birth attendance skills, and the organization of outreach reproductive health camps. The service is also the provision of emergency reproductive health kits and midwifery kits to health facilities and the psycho-social counseling support provided to maternity health workers. Shelter and transition homes were needed for pregnant and postpartum mothers and their newborns, the distribution of dignity kits, motivational kits for affected women and girls, and female community health volunteers [19].

\subsubsection{Monitoring}

The results showed that the supervision of reproductive health programs during the disaster was carried out directly by visiting the refugee camps for disaster victims and supervising the head of the Community Health Center in the Health Office.

This finding is not in line with the results of research conducted by Sanaz Sohrabizadeh year 2018. The study identified that the lack of supervision of pregnancy care for women living in disaster areas, especially for women as heads of families, resulted in these women not getting reproductive health services during disasters [17].

Based on MISP, monitoring during the health crisis emergency response is carried out periodically after one or two weeks of implementing the health MISP. Meanwhile, in the post-crisis stage, monitoring is carried out using existing mechanisms and is used in normal situations, namely the Maternal and Child Health Area Monitoring mechanism which is carried out routinely every month [9].

\subsection{Output Component}

Based on the results, the coverage of reproductive health program indicators during the disaster has not been implemented properly. The implementation of reproductive health programs during a disaster for Women of Childbearing Age is still not fulfilled because this vulnerable group only gets a blood pressure check and is given blood-added tablets. Meanwhile, young women are only given blood-added tablets and do not receive reproductive health services related to reproductive health.

One indicator that has not been achieved in the reproductive health program during the disaster of a health institution is health services and the needs of young 
women. Reproductive health services during a disaster for young women do not yet exist, while the needs of adolescents have not been fully met and some adolescents also do not know about the services and needs for reproductive health during disasters. For this reason, it is expected that health workers can improve reproductive health services and needs during disasters, including priorities for young women. As we know that a woman's reproductive system is delicate and complex in the body. So, it is important to take steps to protect it from infections and injury and prevent problems - including some longterm health problems

The input component of the evaluation of reproductive health program management during disasters is no policy in reproductive health programs during disasters in the health center but is guided by Law No. 24 in the year 2007 about disaster management and MISP. Human Resources in reproductive health programs during disasters that follow the training of crisis emergency response were still limited. Funds for the implementation of reproductive health programs during disasters come from general program funds sourced from the APBN and APBD. Some of the supporting facilities and infrastructure for reproductive health programs during the disaster were already available and in coordination with the head office and local disaster management agency [12].

The process component for reproductive health programs during a disaster does not yet exist specifically.

\section{References}

1. RI Law No. 24 of 2007 concerning 2007 Disaster Management

2. RJ Swatzyna, VK Pillai: The Effects of Disaster on Women's Reproductive Health in Developing Countries. Global Journal of Health Science 2013, 5(4).

3. R Djalante, M Garschagen, F Thomalla, R Shaw : Disaster Risk Reduction in Indonesia: Progress, Challenges, and Issues. Springer International Publishing (2017).

4. Regional Disaster Management Agency (BPBD): Indonesian Disaster Information Data (DIBI). Jakarta: Regional Disaster Management Agency; (2017)

5. Regional Disaster Management Agency (BPBD): Indonesia's Disaster Hazard Index. Jakarta: Regional Disaster Management Agency; (2018)

6. .The Ministry of Health of the Republic of Indonesia: Technical Guidelines for Managing Health Crisis Due to Disasters. Jakarta: Ministry of Health of the Republic of Indonesia; (2007)

7. Azrimaidaliza: Socio-economic and nutritional status of mothers in disaster Prone areas. Andalas Journal of Public Health 2014, 9(1).

8. Suryati: Description of the Needs and Behavior of Young Women during Menstruation in Disaster Emergency Situations in West Sumatra. Journal of Public Health 2013, 7(2):60-65
No special organizational structure has been established for reproductive health during the disaster. The implementation of reproductive health programs during disasters is the provision of services and needs for disaster victims. Supervision is carried out during a disaster, namely directly after a disaster event.

The output component is that the coverage of reproductive health program indicators during the disaster. Mainly, this program is specifically for vulnerable groups, such as women of childbearing age and young women who have not yet received good services and needs.

\section{Conclusion}

Programs of reproductive health during a disaster in the regions are not optimal yet in terms of inputs, processes, and outputs. It is recommended to improve the management of reproductive health programs during disasters regarding specific divisions on health reproductive teams. The Program is not only conducted during a disaster but also before and after a disaster. The program should include such a social empowerment approach provides a broad strategy within which they may acquire resources and procedural means within which they can enhance their own lives or reduce existing vulnerabilities and health outcomes.

9. Ministry of Health of the Republic of Indonesia: Guidelines for the Implementation of the Minimum Initial Service Package (MISP) in a Health Crisis. Jakarta: UNFPA (2017)

10. S I Munauwarah, Hermansyah, Strategy for Reproductive Health Services in Disaster Emergency Situations at the Pidie District Health Office. Aceh Health Ministry Health Polytechnic 2014, 2(1):1-10

11. South Solok District Health Office: South Solok District Health Office Profile Report 2016. South Solok: South Solok District Health Office; (2016)

12. South Solok District Health Office: Profile of South Solok District Health Office 2016. South Solok: South Solok District Health Office; (2016)

13. S Nuruniyah: Evaluation of Reproductive Health Services Prone to Merapi Eruption. Journal of NERS and Midwifery Indonesia 2014, 2(2):51-61.

14. The Ministry of Health of the Republic of Indonesia: Guidelines for the Implementation of the Minimum Initial Service Package (MISP) for Reproductive Health in a Health Crisis. Jakarta: Indonesian Ministry of Health; 2007.

15. S Krause, H Williams, MA Onyango, S Sami, W Doedens, N Giga, et al: Reproductive health services for Syrian refugees in Zaatri Camp and Irbid City, Hashemite Kingdom of Jordan: an evaluation of the Minimum Initial Services Package. Journal Conflict and Health 2015, 9(1).

16. H Fahlevi, M Indriani, RS Oktari: Is the Indonesian disaster response budget correlated with disaster risk? Journal of Disaster Risk Studies 2019, 11(1):759. 
17. S Sohrabizadeh, K Jahangiri, RK Jazani: Reproductive health in the recent disasters of Iran: a management perspective Journal BMC Public Health 2018, 18(389):1-8.

18. Nurhidayati, RS Padmawati, A Wahab: Organizing reproductive health services for post-earthquake refugees in East Lombok. Berita Kedokteran Masyarakat 2020, 36(6).
19. P Chaudhary, G Vallese, M Thapa, VB Alvarez, LM Pradhan, K Bajracharya, K Sekine, S Adhikari, R Samuel, S Goyet: Humanitarian response to reproductive and sexual health needs in a disaster: the Nepal Earthquake 2015 case study. An international journal on sexual and reproductive health and rights 2017, 25(51):25-39 